\title{
Erratum to: Future perspectives for surgical research in Germany
}

\author{
Markus K. Diener • Michael D. Menger • \\ Joachim Jähne • Hans-Detlev Saeger • Ernst Klar
}

Published online: 16 May 2014

(C) Springer-Verlag Berlin Heidelberg 2014

Erratum to: Langenbecks Arch Surg (2014) 399(3):253-62

\section{DOI 10.1007/s00423-014-1178-6}

The original version of this article by Diener et al. unfortunately contained an error concerning table 1 (page 260). For all recruiting trials, in which Cologne was named as University of Principal Investigator, should be correctly stated Witten/Herdecke.

The online version of the original article can be found at http://dx.doi.org/ 10.1007/s00423-014-1178-6.

M. K. Diener

The Study Center of the German Surgical Society, University of Heidelberg, Heidelberg, Germany

M. K. Diener

Department of General, Visceral and Transplantation Surgery, University of Heidelberg, Heidelberg, Germany

M. D. Menger $(\bowtie)$

Institute for Clinical \& Experimental Surgery, Saarland University, 66421 Homburg/Saar, Germany

e-mail: michael.menger@uks.eu

J. Jähne

Department of General and Visceral Surgery, Diakoniekrankenhaus

Henriettenstiftung gGmbH, Hannover, Germany

H.-D. Saeger

Office of Science \& Research, German Surgical Society (DGCH),

Berlin, Germany

E. Klar

Department of General, Thoracic, Vascular and Transplantation

Surgery, University of Rostock, Rostock, Germany 